\title{
Uso, aceptación y repercusión de las redes sociales y los influencers en el sector ecuestre
}

\section{Use, acceptance, and the impact of social networks and influencers on the equestrian sector}

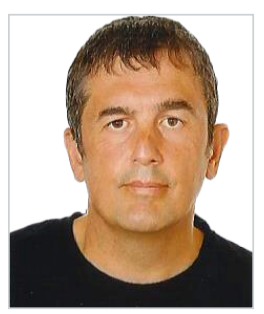

Óscar Gutiérrez Aragón. Director del Departamento de Empresa y Coordinador del Grado en Marketing de la Escuela Universitaria Mediterrani de Barcelona (Universidad de Girona). Doctor en Administración de Empresas por la Universidad de León. Acreditado como Profesor Contratado Doctor y Profesor de Universidad Privada por ANECA. Profesor del Departamento de Empresa de la Universidad de Barcelona. Anteriormente ha sido Profesor de la Universidad de León. Analista Económico e Investigador Principal, responsable de elaborar los informes sociales, económicos y laborales del sector veterinario español para su patronal, la Confederación Empresarial Veterinaria Española (CEVE), adscrita a la Confederación Española de Organizaciones Empresariales (CEOE). Ha publicado manuales de asignatura y diversos artículos de investigación sobre comunicación, marketing, economía ambiental, el sector veterinario y el del automóvil.

Escuela Universitaria Mediterrani (Universidad de Girona), España

oscar.gutierrez@mediterrani.com

ORCID: 0000-0002-4417-6310

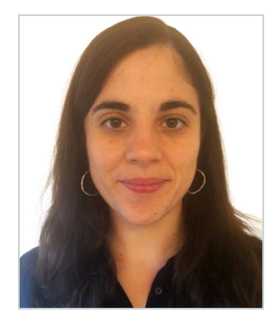

Ariadna Gassiot Melian. Profesora del Área de Estadística del Departamento de Empresa de la Escuela Universitaria Mediterrani de Barcelona (Universidad de Girona). Doctora en Turismo por la Universidad de Girona. Profesora Asociada de la Universidad de Girona. Su principal línea de investigación está basada en el análisis del comportamiento del consumidor, ámbito en el cual ha presentado publicaciones a nivel nacional e internacional. Recientemente ha comenzado a participar en la elaboración de investigaciones estadísticas y empresariales sobre el sector veterinario español.

Escola Universitària Mediterrani de Barcelona (Universidad de Girona), España ariadna.gassiot@mediterrani.com

ORCID: 0000-0001-7212-780X

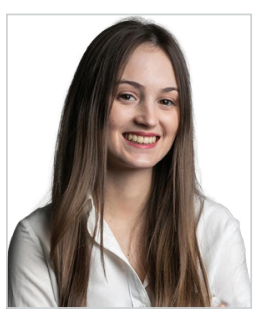

Júlia Alabart Algueró. Investigadora del Departamento de Empresa de la Escuela Universitaria Mediterrani de Barcelona (Universidad de Girona). Graduada en Marketing por la Universidad de Girona. Máster en Dirección de Comunicación y Nuevas Tecnologías por ESIC Business and Marketing School. Sus líneas de investigación son la comunicación, el marketing y el sector ecuestre.

Escola Universitària Mediterrani de Barcelona (Universidad de Girona), España

julia.alabart@mediterrani.com

ORCID: 0000-0001-8694-3306

Cómo citar este artículo:

Gutiérrez Aragón, Ó.; Gassiot Melian, A. y Alabart Algueró, J. (2021). Uso, aceptación y repercusión de las redes sociales y los influencers en el sector ecuestre. Doxa Comunicación, 32, pp. 115-142. 
Recibido: 08/07/2020 - Aceptado: 05/05/2021 - En edición: 02/06/2021 - Publicado: 14/06/2021 Resumen:

Los influencers han alcanzado un lugar preminente en las estrategias comerciales de muchas empresas, ya que transmiten seguridad y confianza a quienes les siguen. Su empleo como herramientas de promoción está bastante generalizado en el ámbito deportivo y están empezando a introducirse en el sector ecuestre en particular. El principal objetivo de este artículo es analizar la opinión que el potencial público receptor del sector tiene sobre las redes sociales y los influencers como nuevas herramientas de comunicación. Se han empleado metodologías de tipo cuantitativo (análisis de datos de fuentes secundarias del sector, estudio y análisis bivariado de los resultados de una encuesta) y cualitativas (entrevistas). El 80\% del público potencial admite que si hubiera más influencers los seguirían. Un $80 \%$ de los usuarios que siguen perfiles de contenido ecuestre siguen principalmente perfiles de tipo informativo y un $65,1 \%$ los aprovechan como fuente de aprendizaje y formación. El 80,7\% declara haber hecho nuevos descubrimientos gracias a un influencer, mientras que un 55,4\% manifiesta haber realizado una compra gracias a ellos. Se concluye que, a pesar de estar en fase de desarrollo en el sector, la utilización de los influencers como herramienta de comunicación resulta muy recomendable.

\section{Palabras clave:}

Influencer; redes sociales; decisión de compra; equitación; comunicación.
Received: 08/07/2020 - Accepted: 05/05/2021 - Early access: 02/06/2021 - Published: 14/06/2021

Abstract:

Influencers have gained an important place in many companies' business strategies since they convey trust and confidence to those who follow them. Their use as promotion tools is widespread in the sports field. However, they are only beginning to be introduced in the equestrian sector. The main objective of this paper is to analyse the opinion that potential target markets have about social networks and influencers as new communication tools. Quantitative methodologies have been used (sector data analysis, survey descriptive and inferential analyses) and qualitative methodologies (interviews). $80 \%$ of the current or potential audience admits that if there were more influencers, they would follow them. $80 \%$ of users who follow equestrian content profiles mainly follow informative ones, and $65.1 \%$ use them as a training and learning resource. $80.7 \%$ of the participants state that they have found new information thanks to an influencer, while $55.4 \%$ admit to making a purchase or applying one of the techniques because of them. Despite the sector being in a development phase, the use of influencers as a communication tool is highly recommended in the equestrian sector.

\section{Keywords:}

Influencer; social networks; purchase decision; horse riding; communication.

\section{Introducción}

El empleo de influencers es cada vez más frecuente en las estrategias comerciales de muchas empresas, que valoran su aportación en la promoción de productos y marcas, y organizaciones de todo tipo, transmitiendo seguridad y confianza a quienes les siguen. Como en muchos otros sectores, este tipo de patrocinios resulta apropiado para el ecuestre, comenzando a ser habitual su utilización en las actividades de marketing. Debido a la falta de estudios existentes en este campo sobre el sector ecuestre y de la hípica, el principal objetivo de este artículo es analizar la posición y visión que se tiene desde diferentes grupos de interés del sector sobre las redes sociales y su impacto en las decisiones de compra y sobre los influencers como nuevas entidades de comunicación en el sector. También se pretende conocer la opinión de los diferentes colectivos sobre la situación actual del sector. 


\section{Marco teórico}

La evolución de la sociedad y sus hábitos de consumo y compra en las últimas décadas ha provocado cambios sustanciales en los líderes de opinión y el interés que suscita la publicidad, sobre todo desde el nacimiento de internet, que aporta un nuevo escenario con vínculos más fáciles y accesibles (Joinson, 2002; Santamaría-De-la-Piedra y Meana, 2017). Su perspectiva global y el acceso a la información de manera inmediata, ha determinado un notable desarrollo de las redes sociales, las cuales han supuesto una revolución en las formas de conexión que antes no eran posibles (Gangadharbatla, 2009; Jhala y Sharma, 2016; Segado-Boj, Díaz-Campo y Navarro-Sierra, 2020), ya que permiten compartir diferentes tipos de información, personal o profesional, con receptores conocidos y desconocidos, logrando mayor alcance e impacto que otras herramientas anteriores, de una forma más fluida y eficaz (Celaya, 2011; Herrera-Harold, 2012).

El perfil típico del consumidor actual pasa por el deseo de una mayor información y exigencia, a la vez comparte información y colabora online (Clavijo-Ferreira, Pérez-Curiel y Luque-Ortiz, 2017; Sanz-Marcos, Jiménez-Marín y Elías-Zambrano, 2019), por lo que no resulta extraño la fortaleza que ha adquirido la figura de prescriptor en blogs y redes, convirtiéndose muchos de ellos en personas influenciadoras gracias a sus opiniones, a su fuerte poder de recomendación, a la gran capacidad de segmentación y al feedback que puede ofrecer (Castelló-Martínez y Pino-Romero, 2015a; Muiños-Morales, 2017). El influencer, configurado de este modo, es una figura relativamente reciente, caracterizado por tener la credibilidad y la habilidad de condicionar actitudes y comportamientos de otras personas, convirtiéndose en ocasiones en líderes de opinión (Freberg et al., 2011; Gómez-Nieto, 2018; Martínez-Sala, Monserrat-Gauchi y Segarra-Saavedra, 2019). Su importancia social ha aumentado de forma tal que actualmente entre un $70 \%$ y un $85 \%$ de usuarios (dependiendo del estudio) declaran seguir a influencers en redes sociales, por lo que la comunicación publicitaria de grandes y pequeñas marcas se ha ido adaptando a este fenómeno comercial, contratándolos a cambio de publicitar sus productos, cuando se platean acciones en redes sociales (IAB Spain, 2019; Establés, Guerrero-Pico y Contreras-Espinosa, 2019; Sanz-Marcos, Jiménez-Marín y Elías-Zambrano, 2019).

El mundo empresarial se ha percatado del potencial del uso de las redes hasta considerarlas un elemento imprescindible de promoción y comunicación del marketing, aunque, la mayor parte de las veces, las acciones en redes y con influencers se desarrollan de forma sinérgica con otras acciones de publicidad y relaciones públicas (Kimmel y Kitchen, 2014; Santamaría-de-la-Piedra y Meana, 2017; Navío Navarro, González-Díez y Puebla-Martínez, 2018; Coll y Micó-Sanz, 2019). De todos modos, si bien es cierto que un número significativo de profesionales del marketing apuestan por este tipo de campañas, la medición del $R O I$ (retorno sobre la inversión) en las redes resulta complicado de calcular, dificultando así la medición del éxito en campañas de este tipo (Sánchez-Jiménez, 2018; Mejía-Llano, 2019).

Por otra parte, en una época en que la mayor parte de deportes ha ampliado el número de practicantes y de federados (Instituto Nacional de Estadística, 2019; Ministerio de Educación, Cultura y Deporte, 2019) y el deporte en sí es considerado un producto de consumo muy relevante que contribuye tanto al desarrollo personal como al de la economía (Álvarez-Alday y Fernández-Villarán-Ara, 2012), el marketing deportivo también ha disfrutado de un gran desarrollo, parejo al incremento de la comercialización de los eventos deportivos de gran nivel, al progresivo crecimiento de la notoriedad social de entidades y deportistas y a la evidencia de que la utilización del deporte en la promoción de productos suele pro- 
porcionar un aumento de la fidelidad de los clientes y de la facturación de las empresas (Alonso-Rivas y Grande-Esteban, 2004; Stanton, Etzel y Walker, 2007; Schlesinger, Alvarado-Herrera y Martí-Parreño, 2012). En cualquier caso, esta efectividad mejora cuando hay una buena adecuación entre deportista y marca, siendo peor si la relación no es congruente, pues reduce la credibilidad tanto del deportista como de la marca (Tripp, Jensen y Carlson, 1994; Chien, Cornwell y Pappu, 2011; Braunstein-Minkove, Zhang y Trail, 2011; Rossiter y Smidts, 2012; Martínez, 2015; Gómez-Nieto, 2018).

Además, esta gran trascendencia social y económica del deporte ha otorgado en muchos casos un valor añadido al ocio, factor incuestionable de desarrollo y realización personal, que atrae el interés por parte de las empresas para depositar parte de sus acciones de marketing (De-la-Cruz-Ayuso, 2006; Reverter-Masia y Plaza-Montero, 2011), puesto que es considerado por gran parte de los individuos un elemento clave para diferenciarse del resto y alejarse del mero consumo para la subsistencia (Ritzer, 2001; Antón-Clavé, 2007). La industria del ocio tiene mucho potencial explotable, ya que el aumento del compromiso afectivo y la fidelidad de los consumidores hacia los diferentes productos y marcas conduce a las empresas a integrar la gestión de la experiencia y el ocio que experimenta el cliente como elemento clave para mantener la competitividad (Grigorovici y Constantine, 2004; Parreño, 2010; Cabeza y Prat, 2012). Así, el marketing de ocio debe apostar por la creación de valor añadido para el cliente a través de la generación de sentimientos y emociones positivas allí donde confluyen empresa y cliente, desde antes de la compra, transmitiendo información y generando notoriedad, hasta, en su caso, el servicio postventa (Moral-Moral y Fernández-Alles, 2012; Logroño-Tormo y Llopis-Goig, 2020).

En lo que se refiere al deporte y ocio utilizando caballos, resulta relevante recordar que, aunque, en la actualidad, la mayor parte del sector ecuestre está dedicado a ese tipo de actividades, destinadas en gran medida a satisfacer las necesidades de bienestar y autorrealización personal, habitualmente el uso de caballos ha estado ligado al trabajo en la agricultura y la industria (Mihók y Castejón-Montijano, 2016; González-López, 2018). Paradójicamente, este cambio en los usos y costumbres del sector ha motivado que este tenga un mayor impacto económico en la actividad económica española, que se traduce en una aportación al PIB de más de 5.000 millones de euros anuales (Deloitte, 2013; Real Federación de Hípica Española, 2018).

Aunque tradicionalmente la sociedad ha considerado la hípica como un deporte elitista, también se advierte en los últimos años un cambio de tendencia en este sentido, acompañado de un aumento de caballos y personas federadas (prácticamente el doble de mujeres que hombres, siendo uno de los pocos deportes que es totalmente paritario, pues compiten en igualdad ambos géneros), el incremento del interés del público por la emisión televisiva periódica del cada vez mayor número de competiciones nacionales e internacionales y la aparición de nuevas plataformas como blogs, canales de YouTube o perfiles de Instagram que contribuyen a dar más visibilidad a estos eventos (Ministerio de Educación, Cultura y Deporte, 2015; Arias-González, 2018; Real Federación de Hípica Española, 2018; Tirado, 2018; Ministerio de Educación, Cultura y Deporte, 2019).

A la par, se ha intensificado la realización de eventos hípicos relacionados con el ocio, muchos de ellos relacionados con la promoción del caballo Pura Raza Español, que comportan un importante impacto económico en las localidades donde se celebran (Sánchez-Guerrero, 2016; Asociación Nacional de Criadores de Caballos de Pura Raza Española, 2019). De hecho, la industria relacionada con la ganadería equina también ha experimentado un destacado crecimiento económico, 
debido al aumento del número de explotaciones equinas y del comercio de ejemplares, constituyéndose en un generador de empleo en las zonas más rurales (Luque-Gil, 2006; Federación Española de Asociaciones de Ganado Selecto, 2017; Ministerio de Agricultura, Pesca y Alimentación, 2019).

Es de general aceptación entre los expertos, que el deporte de la hípica y el sector en general carece de una visión global, pues el caballo se utiliza en muy diversos ámbitos (turismo, educación, deporte, ocio), pero no existen planes estratégicos conjuntos que permitan renovar el sector y explotar al máximo sus posibilidades (Deloitte, 2013; Real Federación de Hípica Española, 2018; Tirado, 2018). Evidentemente, como en cualquier otro sector, las empresas ecuestres, partiendo de factores productivos, ofrecen sus productos o servicios con la intención de que los consumidores los adquieran (Gutiérrez-Aragón, 2016), y es en este tipo de mercados, por naturaleza muy competitivos, donde cobra especial importancia en la actualidad la figura del prescriptor, pues los consumidores valoran más las opiniones de personas de referencia o confianza (como son los influencers) que los mensajes que difunden las propias empresas sobre sus productos (Castelló-Martínez y Del-Pino-Romero, 2015b; Díaz-Iglesias, 2017).

De hecho, los presupuestos dedicados a acciones de marketing con influencers son cada vez más grandes y producen resultados medibles, con un impacto directo en ventas, un retorno de inversión real y un efecto más inmediato que la publicidad tradicional, tanto en los sectores en los que ha venido siendo más habitual (moda y belleza), como en otros a los que paulatinamente se va generalizando su utilización, entre los que, sin duda, se encuentra el ecuestre (Venegas, 2015; Aramendía-Muneta, 2017; Buttle y Groeger, 2017).

\section{Metodología}

Tal y como se ha apuntado en un epígrafe anterior, el principal objetivo de este estudio es el análisis de la valoración de los diferentes grupos de interés del sector ecuestre sobre las redes sociales y su impacto en las decisiones de compra, así como la estimación que se tiene de los influencers como entidades de comunicación en el sector. De forma desagregada será posible determinar, entre otros objetivos de la investigación, la evolución del sector, la valoración de su público objetivo y los principales tipos de actividades que habitualmente llevan a cabo las personas que ejercen la práctica ecuestre, prestando especial atención a si existe alguna diferenciación por género. Se pretende también conocer la influencia de las redes sociales sobre las decisiones de compra en el sector ecuestre, el interés del público del sector por seguir contenidos del mundo hípico y el grado de utilización de las redes sociales para ello. Por otro lado, se desea precisar el grado de aceptación y seguimiento de influencers en este campo, los tipos de perfiles seguidos, así como los tipos de contenidos principalmente demandados por su público y las recomendaciones o influencias que están dispuestos a aceptar o asumir. Por último, se pretende concretar los distintos tipos de influencers existentes en el mundo de la equitación, la opinión sobre acuerdos y patrocinios con influencers y la conveniencia de utilizar los influencers en el sector ecuestre como herramienta de comunicación.

Para ello, el presente trabajo pretende abordar un estudio de resultados utilizando triangulación metodológica, técnica de análisis de datos especialmente valorada en estudios relacionados con el marketing y la comunicación porque habitualmente aumenta la calidad de las contribuciones (Dahlstrom, Nygaard y Crosno, 2008; Dzwigol, 2020), estimándose 
además que solo con la aplicación y combinación de varias metodologías, tanto de análisis cuantitativo como cualitativo, es posible obtener una visión completa del tema objeto de la investigación (Webb et al. 1966; Denzin, 1970; Bericat, 1998; Olsen, 2004; Forni y De-Grande, 2020).

A nivel cuantitativo, se lleva a cabo el análisis de datos procedentes de fuentes secundarias, con el fin de determinar principalmente la evolución en cifras del sector en los últimos años, y de una encuesta (fuente primaria), que permitirá conocer, entre otras cuestiones, la valoración del público objetivo, las actividades que habitualmente practican, su grado de utilización de las redes sociales y la influencia sobre las decisiones de compra, el interés por seguir contenidos ecuestres y cuáles son los más demandados, los tipos de perfiles más seguidos, el grado de aceptación y seguimiento de influencers y las recomendaciones que estarían dispuestos a aceptar. Por otro lado, la técnica cualitativa aplicada ha sido la de la entrevista semiestructurada, tanto individual como en grupo, realizada a personas con funciones diversas dentro del sector (fuente primaria), que, de modo complementario, contribuirán a conocer mejor la evolución y situación del sector, la valoración de la utilización de las redes sociales y su influencia sobre la decisión de compra y la opinión sobre acuerdos y patrocinios con influencers. En su conjunto, la aplicación de todos estos elementos de análisis debería permitir determinar la conveniencia o no de utilizar influencers en el ámbito de la comunicación en el sector ecuestre.

La encuesta de 13 preguntas cerradas se ha implementado con la intención de determinar el grado de conocimiento y la opinión sobre los influencers y el uso de las redes sociales en las actividades hípicas y otras del sector ecuestre. Las preguntas que se incluyen en la encuesta están directamente relacionadas con los objetivos de esta y se han diseñado principalmente de acuerdo con una serie de conclusiones de estudios previos a nivel general sobre el marketing de influencers (Gretzel, 2018; Kádeková y Holiencinová, 2018; Jin, Muqaddam y Ryu, 2019; Stubb, Nyström y Colliander, 2019; Campbell y Farrell, 2020) (tabla 1). 
Tabla 1. Diseño de la encuesta

\begin{tabular}{|c|c|c|}
\hline Concepto & Objetivos & Investigaciones previas \\
\hline $\begin{array}{l}\text { Influencia de las } \\
\text { redes sociales en } \\
\text { las decisiones de } \\
\text { compra }\end{array}$ & $\begin{array}{l}\text { Conocer la influencia de las redes } \\
\text { sociales sobre las decisiones de } \\
\text { compra en el sector ecuestre. } \\
\text { Precisar las recomendaciones o } \\
\text { influencias que están dispuestos a } \\
\text { aceptar o asumir. }\end{array}$ & $\begin{array}{l}\text { Stubb, Nyström y Colliander (2019): la puesta en práctica de acuerdos o } \\
\text { patrocinios incrementa la credibilidad de la fuente y del mensaje y crea } \\
\text { una opinión más positiva en el receptor. } \\
\text { Gretzel (2018): cuando se construye una buena relación marca-influencer, } \\
\text { las estrategias de marketing basadas en influencers pueden tener unos } \\
\text { mejores resultados que otras estrategias. }\end{array}$ \\
\hline $\begin{array}{l}\text { Interés por } \\
\text { contenidos } \\
\text { especializados y } \\
\text { uso de las redes }\end{array}$ & $\begin{array}{l}\text { Conocer el interés del público } \\
\text { del sector por seguir contenidos } \\
\text { del mundo hípico y el grado de } \\
\text { utilización de las redes para ello. }\end{array}$ & $\begin{array}{l}\text { Gretzel (2018): existe cada vez un mayor interés en analizar una tendencia } \\
\text { actual como la emergencia de perfiles de influencers más profesionales. }\end{array}$ \\
\hline $\begin{array}{l}\text { Aceptación y } \\
\text { transmisión de } \\
\text { confianza de } \\
\text { influencers }\end{array}$ & $\begin{array}{l}\text { Concretar el grado de aceptación } \\
\text { y seguimiento de influencers en el } \\
\text { ámbito ecuestre. }\end{array}$ & $\begin{array}{l}\text { Kádeková y Holiencinová (2018): los consumidores esperan que } \\
\text { las marcas establezcan contacto a través de colaboraciones con los } \\
\text { influencers apropiados (un contacto más directo que transmite más } \\
\text { confianza). El número de seguidores no define el impacto, sino la } \\
\text { experiencia y credibilidad que pueden transmitir. }\end{array}$ \\
\hline $\begin{array}{l}\text { Tipo de perfiles } \\
\text { seguidos y } \\
\text { contenidos } \\
\text { demandados }\end{array}$ & $\begin{array}{l}\text { Precisar los tipos de perfiles } \\
\text { seguidos y los contenidos } \\
\text { principalmente demandados por } \\
\text { el público de este ámbito. } \\
\text { Concretar los distintos tipos de } \\
\text { influencers existentes en el mundo } \\
\text { de la equitación. }\end{array}$ & $\begin{array}{l}\text { Jin, Muqaddam y Ryu (2019): la diferencia entre tipos de perfiles de } \\
\text { influencers o celebrities (tradicionales y de Instagram) produce diferencias } \\
\text { en la percepción de autenticidad y sentimiento de relación seguidor- } \\
\text { influencer. } \\
\text { Campbell y Farrell (2020): El contenido de los microinfluencers influye en } \\
\text { las ventas de manera significativa porque los seguidores encuentran sus } \\
\text { recomendaciones más auténticas que las que hacen los influencers más } \\
\text { genéricos. Es muy conveniente entender las diferencias entre tipos de } \\
\text { influencers, sus habilidades, sus enfoques, poder, etc. }\end{array}$ \\
\hline $\begin{array}{l}\text { Conveniencia del } \\
\text { uso de influencers } \\
\text { como herramienta } \\
\text { de comunicación }\end{array}$ & $\begin{array}{l}\text { Analizar la conveniencia de } \\
\text { utilizar los influencers en el sector } \\
\text { ecuestre como herramienta de } \\
\text { comunicación. }\end{array}$ & $\begin{array}{l}\text { Gretzel (2018): los especialistas en marketing tienen que tener en cuenta } \\
\text { los influencers en su estrategia de comunicación porque en muchos casos } \\
\text { puede ser mejor herramienta que otras alternativas. }\end{array}$ \\
\hline
\end{tabular}

Fuente: elaboración propia

La muestra de la encuesta está compuesta por 269 personas residentes en España y que tienen algún tipo de relación con el mundo del caballo. Se calcula que la población aproximada en España relacionada de alguna manera con el sector 
ecuestre es de unos 113.000 individuos, cifra conformada por la suma del personal ocupado en el sector, 61.000 trabajadores aproximadamente (Deloitte, 2013), más el número total de federados, unos 52.000 (Real Federación Hípica Española, 2019c). Para garantizar que los encuestados tuvieran relación con el campo objeto de estudio, la encuesta se distribuyó de manera exclusiva a través de métodos de comunicación específicos del sector ecuestre (revistas especializadas, centros hípicos e influencers, entre otros). Además, con una primera pregunta filtro, que no dejaba continuar con la encuesta si la respuesta era negativa, se les preguntaba expresamente por esta relación. Así, para un intervalo de confianza del 95\% y una proporción de la población del $80 \%$ (cifra discreta considerando que todos los entrevistados pertenecen a los grupos de interés del sector) el error muestral es de $\pm 4,77 \%$. Se ha utilizado el programa estadístico SPSS para cruzar las variables obtenidas de la encuesta con el fin de buscar relaciones de entre ellas.

Se llevaron a cabo dos tipos de entrevistas, una de forma conjunta a un grupo de expertos pertenecientes al club hípico Quadres d'en Blai (Riudoms, Tarragona), todos con larga experiencia en el mundo del caballo, y una serie de entrevistas individuales realizadas a personas relacionadas con diversos aspectos del sector, manteniendo una estructura y unas preguntas similares, con el fin de poder comparar la visión de los diferentes stakeholders. Las entrevistas se realizaron principalmente entre los meses de febrero y mayo de 2020, cuando la población española se encontraba en situación de confinamiento debido a la pandemia de COVID-19, por lo que la mayor parte se llevó a cabo mediante videoconferencia. Para el diseño de las cuestiones principales que conformaban las entrevistas se prestó especial atención a trabajos previos que ponían de manifiesto la influencia sobre la decisión de compra de la utilización de redes sociales y influencers y advertían del incremento de la credibilidad sobre el receptor cuando existen acuerdos y patrocinios con influencers (Jin, Muqaddam, y Ryu, 2019; Stubb, Nyström y Colliander, 2019).

\section{Resultados}

\subsection{Análisis de datos procedentes de fuentes secundarias oficiales}

Se ha acudido a fuentes secundarias con el objetivo de poder concretar la evolución de diversos indicadores relacionados con el ámbito ecuestre en los últimos años. Los datos de fuentes oficiales sobre el mundo de la hípica en España muestran un sector en moderado crecimiento, en el que se ha producido entre 2014 y 2019 un incremento del 8,82\% en el número de licencias expedidas a jinetes (52.405 en 2019) y un 2,07\% en el de clubes deportivos federados (837 en 2019) (Ministerio de Educación Cultura y Deporte, 2019; Real Federación de Hípica Española, 2019c). En ese mismo periodo, se incrementan sustancialmente el número de competiciones, de deportistas, de caballos participantes y de salidas a pista en tres de las disciplinas olímpicas (Concurso Completo, Doma Clásica y Salto de Obstáculos), mientras que la disciplina de Raid, aunque aumenta en número de competiciones un 14,55\% disminuye la participación en ellas en un 33,68\% (tabla 2). En cuanto a competiciones de carácter internacional celebradas en España, destaca notablemente el crecimiento de concursos realizados de Doma Clásica y de Salto de Obstáculos, creciendo en un $440 \%$ y 344,12\% respectivamente. También se incrementaron un 43,75\% las competiciones en la disciplina de Raid (Real Federación de Hípica Española, 2019a). La asistencia a las 511 competiciones que se celebraron en el año 2019 alcanzó los 661.800 espectadores, siendo la disciplina 
de Salto de Obstáculos (con 564.000) la que más personas atrajo a las instalaciones deportivas (Real Federación de Hípica Española, 2019b).

Tabla 2. Comparación de competiciones nacionales en España, 2014-2019

\begin{tabular}{|c|c|c|c|c|c|c|c|c|c|c|c|c|}
\hline \multirow{2}{*}{$\begin{array}{c}\text { Concursos } \\
\text { Nacionales en } \\
\text { España }\end{array}$} & \multicolumn{3}{|c|}{ Concurso Completo } & \multicolumn{3}{|c|}{ Doma Clásica } & \multicolumn{2}{|c|}{$\begin{array}{c}\text { Salto de } \\
\text { Obstáculos }\end{array}$} & \multicolumn{4}{|c|}{ Raid } \\
\hline & 2014 & 2019 & $\begin{array}{l}\text { Var. } \\
14-19\end{array}$ & 2014 & 2019 & $\begin{array}{l}\text { Var. } \\
14-19\end{array}$ & 2014 & 2019 & $\begin{array}{l}\text { Var. } \\
14-19\end{array}$ & 2014 & 2019 & $\begin{array}{l}\text { Var. } \\
14-19\end{array}$ \\
\hline Competiciones & 14 & 32 & $128,57 \%$ & 60 & 71 & $18,33 \%$ & 160 & 174 & $8,75 \%$ & 55 & 63 & $14,55 \%$ \\
\hline Deportistas & 166 & 283 & $70,48 \%$ & 691 & 873 & $26,34 \%$ & 1.385 & 1.972 & $42,38 \%$ & 95 & 63 & $-33,68 \%$ \\
\hline Caballos & 213 & 362 & $69,95 \%$ & 965 & 1.261 & $30,67 \%$ & 2.321 & 3.441 & $48,26 \%$ & 96 & 63 & $-34,38 \%$ \\
\hline Salidas a pista & 1.869 & 3.294 & $76,24 \%$ & 4.313 & 5.897 & $36,73 \%$ & 23.010 & 32.194 & $39,91 \%$ & 134 & 81 & $-39,55 \%$ \\
\hline
\end{tabular}

Fuente: Real Federación de Hípica Española (2019a)

\subsection{Análisis cuantitativo de fuentes primarias}

Los objetivos principales del análisis cuantitativo de fuentes primarias pasan por conformar una visión general de la población con interés en el sector ecuestre, conocer las actividades que habitualmente practican, evaluar el grado de conocimiento y la interacción con las redes sociales y los influencers relacionados con las actividades hípicas, así como su influencia sobre las decisiones de compra. Además, se pretende determinar los tipos de perfiles más seguidos, el grado de seguimiento de los influencers y las recomendaciones que el público del sector estaría dispuesto a aceptar. Para ello, se ha realizado una encuesta a una muestra compuesta por individuos residentes en España que tienen algún tipo de relación con el mundo del caballo y, por consiguiente, con el sector objeto de este estudio. Predomina entre los encuestados la presencia de mujeres con un $85,5 \%$ frente a un $14,5 \%$ de hombres, lo cual puede considerarse dentro de lo esperable, ya que se trata de un deporte en el que aproximadamente el 70\% de las licencias federativas corresponden a mujeres (Hontangas-Carrascosa, Mestre-Sancho y Orts-Delgado, 2018). Además, la gran mayoría de las personas que han contestado la encuesta son jóvenes (un 93,3\% menor de 35 años), siendo razonable teniendo en cuenta el tema analizado y que la mayor parte de los deportes se suelen practicar principalmente en edades tempranas. 
Gráfico 1. Relación con el mundo del caballo

\begin{tabular}{|r|c|}
\hline Solía tener relación en el pasado, pero ya no & $5,6 \%$ \\
Tengo un familiar o amigo en este mundo & $4,8 \%$ \\
Es un hobby & $16,4 \%$ \\
Mi profesión está relacionada con caballos & $11,9 \%$ \\
Soy deportista a nivel profesional & $8,2 \%$ \\
Practico equitación regularmente & \\
\hline
\end{tabular}

Fuente: elaboración propia

Todos los encuestados tienen o han tenido algún tipo de relación con el mundo ecuestre, ya sea directa o indirecta (gráfico 1), destacando el hecho de que el 69,5\% tienen una relación amateur con este deporte, practicando equitación de manera regular un 53,1\% y considerándolo un hobby o una afición el 16,4\%. Por otra parte, un 20,1\% de los encuestados tiene una relación profesional con el sector, ya como deportistas profesionales (8,2\%) o como trabajadores del sector (11,9\%).

Un 99,6\% de los participantes en la encuesta utiliza habitualmente las redes sociales, siendo el 95,2\% de ellos seguidores de cuentas o perfiles relacionados con el mundo del caballo. La red social más utilizada para seguir contenido ecuestre es Instagram (95,5\% de los usuarios que afirman usar esta red social), seguida de YouTube $(65,8 \%)$, Facebook $(40,1 \%)$ yWhatsApp $(27,9 \%)$. En menor medida se utilizan plataformas de blogs $(21,2 \%)$ y Twitter $(8,9 \%)$, siendo el resto casi residuales. Entre los contenidos que más interés suscitan se encuentran los que proporcionan formación o nuevos conocimientos sobre temas ecuestres (así lo admiten el 80,3\% de los encuestados) y los meramente informativos (77,3\%). Por otro lado, los perfiles más seguidos son los de deportistas $(77,3 \%)$, los de clubes $(76,2 \%)$, las tiendas especializadas $(72,1 \%)$ y los canales oficiales $(69,5 \%)$, destacando también los perfiles de influencers $(57,6 \%)$ y fotografía ecuestre $(55,4 \%)$ (gráfico 2). 
Gráfico 2. ¿Qué tipo de perfiles sigues?

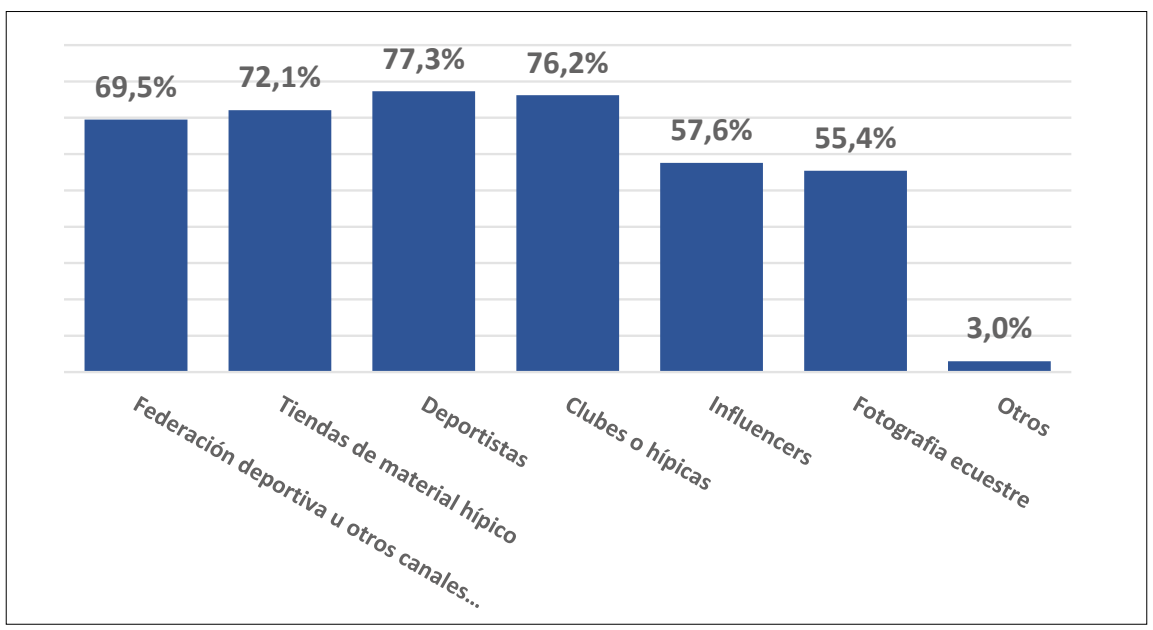

Fuente: elaboración propia

Gráfico 3. Grado de influencia de las redes en las decisiones de compra

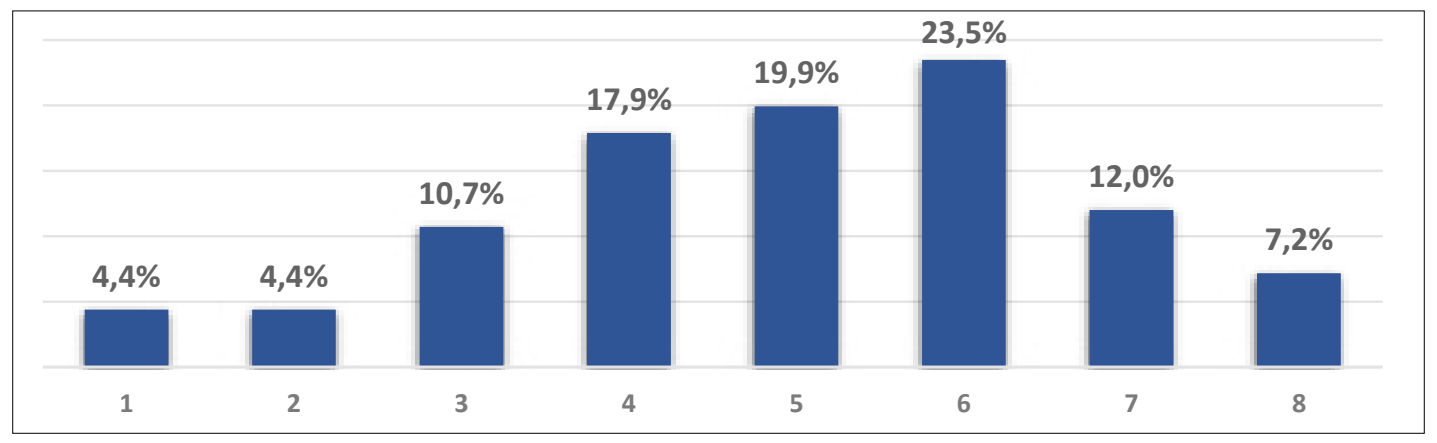

Fuente: elaboración propia

En este contexto, el 80,7\%, de los encuestados reconoce haber descubierto alguna cosa que no sabía gracias a un influencer. Por otro lado, un 55,4\% admite haber consumido un producto o utilizado una técnica o cualquier o elemento promocionado por uno de estos profesionales. En cualquier caso, la mayoría de los encuestados atribuyen a las redes sociales una importancia elevada en cuanto a su influencia en las decisiones de compra de los consumidores. Así, un $61,3 \%$ de los participantes consideraron que la influencia de las redes sociales en la compra se situaba entre los grados 4 y 6 sobre 8. Un $19,2 \%$ les atribuyeron una influencia muy alta. La media ponderada de las respuestas arroja un resultado de 4,99 puntos sobre 8 (gráfico 3). 
El principal motivo que conducen a los usuarios a seguir perfiles de influencers ecuestres es la búsqueda de nuevos conocimientos y aprendizaje (86,3\%). Más de la mitad de los encuestados $(52,8 \%)$ concede que el hecho de que les guste el contenido es un aspecto decisivo, mientras que un $41,3 \%$ los sigue por entretenimiento y un $34,2 \%$ por conocer nuevos productos (gráfico 4). Por otra parte, el sentir mayoritario sobre los influencers dentro del mundo de la hípica se debate entre quienes piensan que ayudan a dar a conocer el sector $(56,9 \%$ y los que consideran que proporcionan información a personas una vez ya forman parte de este mundo (53,2\%). Muchos encuestados también destacan el hecho de que aportan una visión modernizadora en la manera de proporcionar información $(44,6 \%)$ y que son un elemento importante para ayudar a los principiantes ( $48 \%$ ). Solo un $13,8 \%$ consideran que pueden ayudar poco y un $4,8 \%$ consideran que no son relevantes.

Gráfico 4. ¿Por qué motivos sigues a influencers ecuestres?

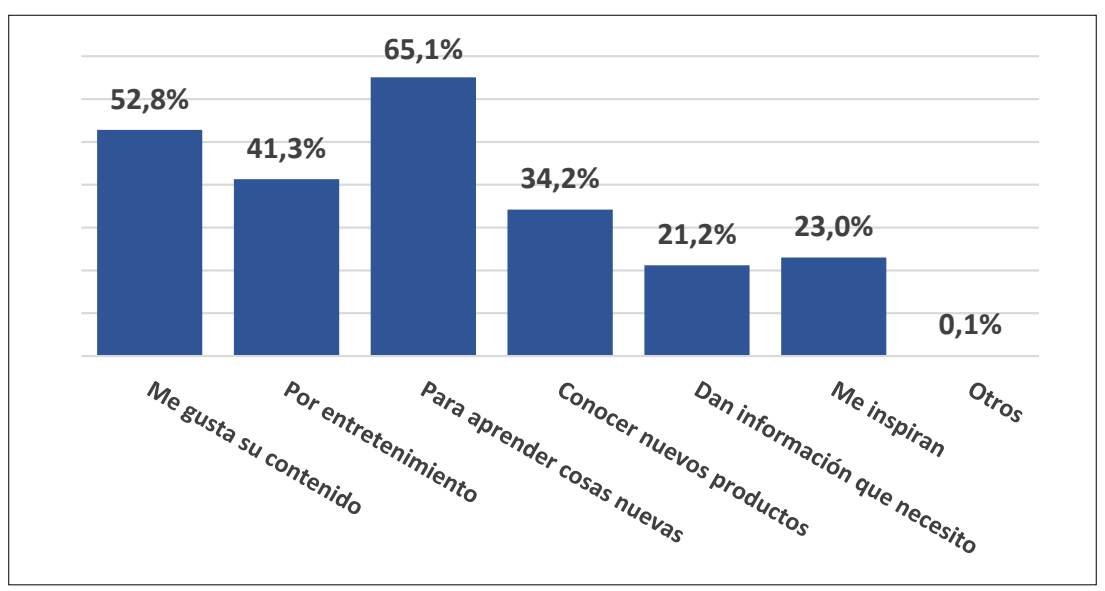

Fuente: elaboración propia

La mayor parte de los participantes en la encuesta conocen diversos medios que proporcionan contenido ecuestre los usuarios, siendo el más popular la revista especializada Ecuestre (70,3\%). También afirman conocer la cuenta del influencer internacional Matt Harnacke un 60,2\%, y las de influencers nacionales como Natalia de NMV Horses $(57,20 \%)$ y Silvia de My Horseback View (50,20\%). Solamente un 5,2\% de los participantes afirmaron no conocer ningún medio. Interpelados sobre si seguirían a más influencers si hubiera más cuentas de contenido ecuestre en español, la respuesta mayoritaria fue positiva, pues el $80,7 \%$ de los encuestados afirmaron que sí lo harían.

Se ha utilizado el programa estadístico SPSS para cruzar las variables obtenidas de la encuesta y buscar relaciones entre ellas. Los análisis se han fundamentado en dos de las características sociodemográficas más utilizadas para analizar los perfiles (edad y sexo) y en la variable Relación personal con el mundo de la equitación. Los resultados obtenidos de este análisis indican, en principio, que no se observa una relación del sexo con el tipo de perfiles a los que se sigue en redes, pues todos presentan valores de significación muy bajos. Por ello, se deriva que, tanto hombres como mujeres, siguen 
sin preferencias a los diferentes tipos de perfiles. Tampoco se observan diferencias significativas de proporciones con relación al sexo para el tipo del contenido que se sigue en redes. Sí se ha detectado, sin embargo, una relación entre la variable sexo y la cuestión de seguir a más influencers ecuestres en caso de que los hubiera (tabla 3). Se observa una relación débil $(\mathrm{V}=0,199$ y $\mathrm{p}=0,001)$, pero se puede afirmar que las mujeres se muestran más dispuestas a seguir más perfiles que los hombres.

Tabla 3. Sexo *Si hubiera más influencers ecuestres, ¿los seguirías?

\begin{tabular}{|c|c|c|c|c|c|}
\hline \multirow{2}{*}{\multicolumn{3}{|c|}{$\begin{array}{l}\text { Tabla cruzada. } \\
\text { Sexo*Si hubiera más influencers ecuestres, ¿̇los seguirías? }\end{array}$}} & \multicolumn{2}{|c|}{ Sexo } & \multirow[b]{2}{*}{ Total } \\
\hline & & & \multirow{2}{*}{$\begin{array}{r}\text { Hombre } \\
15\end{array}$} & \multirow{2}{*}{$\begin{array}{r}\text { Mujer } \\
37\end{array}$} & \\
\hline \multirow{4}{*}{$\begin{array}{l}\text { Si hubiera más influencers } \\
\text { ecuestres, ¿los seguirías? }\end{array}$} & \multirow[b]{2}{*}{ No } & Recuento & & & 52 \\
\hline & & $\begin{array}{l}\text { Recuento } \\
\text { esperado }\end{array}$ & 7,5 & 44,5 & 52,0 \\
\hline & \multirow{2}{*}{ Sí } & Recuento & 24 & 193 & 217 \\
\hline & & $\begin{array}{l}\text { Recuento } \\
\text { esperado }\end{array}$ & 31,5 & 185,5 & 217,0 \\
\hline \multirow[b]{2}{*}{ Total } & & Recuento & 39 & 230 & 269 \\
\hline & & $\begin{array}{l}\text { Recuento } \\
\text { esperado }\end{array}$ & 39,0 & 230,0 & 269,0 \\
\hline
\end{tabular}

Fuente: SPSS a partir de datos propios

Para realizar los análisis en función de la edad se han realizado dos segmentaciones diferentes. En primer lugar, se han segmentado las respuestas de manera más específica y concreta según cinco grupos de edad (considerando que tanto profesional como deportivamente o como ocio el acceso a las actividades del sector se suele producir en edades muy tempranas): menores de 14 años, de 15 a 18 años, de 19 a 24 años, de 25 a 34 años y 35 años o más.

Los resultados obtenidos así determinan que la franja de edad tiene relación significativa con el tipo de perfiles que siguen los encuestados $(\mathrm{V}=0,248$ y p=0,002). En el caso de tiendas, por ejemplo, se observa que el conjunto de los menores de 18 años y el segmento de 25 a 34 siguen más a este perfil de lo que cabría esperar con independencia total de las variables (tabla 4). Igualmente, en el caso de los influencers se observa que los que siguen a estos perfiles con más proporción de lo que cabe esperarse son estos dos mismos segmentos de edad ( $V=0,348$ y $\mathrm{p} \leq 0,000)$. 
Tabla 4. Edad1 *Tiendas de material hípico y Edad1 *Influencers

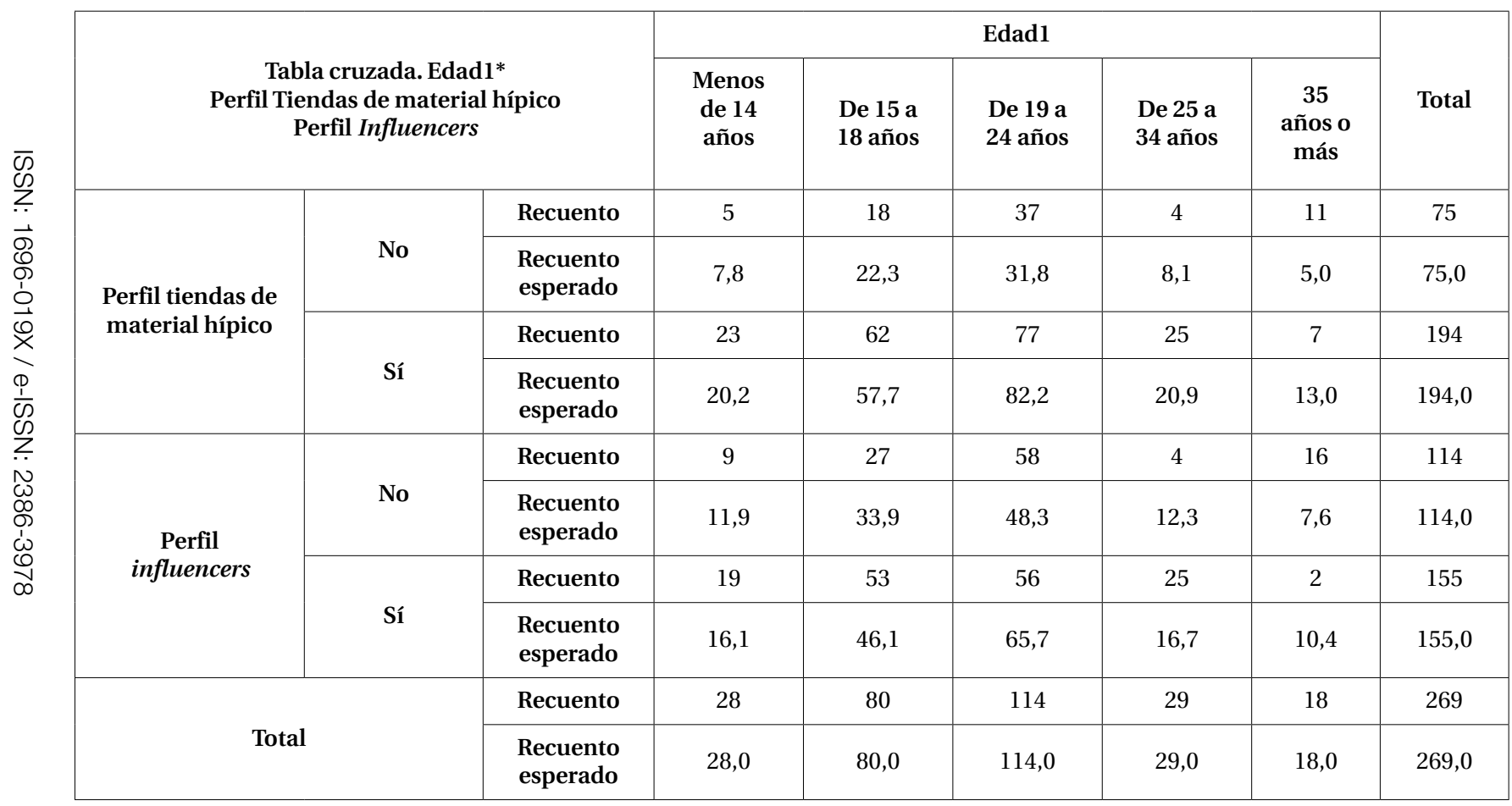

Fuente: SPSS a partir de datos propios

Por otra parte, existen relaciones significativas entre grupos de edad y algunos de los motivos que llevan a seguir estos perfiles. Existe relación débil-media pero significativa entre grupos de edad y los motivos me gusta su contenido ( $\mathrm{V}=0,271$ y $\mathrm{p}=0,001)$ y sirve para aprender cosas nuevas $(\mathrm{V}=0,263 \mathrm{y} \mathrm{p}=0,001)$. Los análisis realizados destacan el hecho de que a los menores de 18 años les atrae el gusto por el contenido mientras que los segmentos de 19 a 25 y los mayores de 35 muestran más interés cuando sirve para aprender cosas nuevas (tabla 5). 
Tabla 5. Edad1 *Me gusta su contenido y Edad1 *Para aprender cosas nuevas

\begin{tabular}{|c|c|c|c|c|c|c|c|c|}
\hline \multirow{2}{*}{\multicolumn{3}{|c|}{$\begin{array}{c}\text { Tabla cruzada. Edad1* } \\
\text { Motivo Me gusta su contenido } \\
\text { Motivo Para aprender cosas nuevas }\end{array}$}} & \multicolumn{5}{|c|}{ Edad1 } & \multirow{3}{*}{$\begin{array}{r}\text { Tota } \\
127\end{array}$} \\
\hline & & & \multirow{2}{*}{$\begin{array}{c}\text { Hasta } 14 \\
\text { años } \\
7\end{array}$} & \multirow{2}{*}{$\begin{array}{c}\begin{array}{c}\text { De } 15 \text { a } 18 \\
\text { años }\end{array} \\
30\end{array}$} & \multirow{2}{*}{$\begin{array}{c}\text { De } 19 \text { a } 24 \\
\text { años } \\
61\end{array}$} & \multirow{2}{*}{$\begin{array}{c}\begin{array}{c}\text { De } 25 \text { a } 34 \\
\text { años }\end{array} \\
14\end{array}$} & \multirow{2}{*}{$\begin{array}{c}\begin{array}{c}35 \text { años } \\
\text { o más }\end{array} \\
15\end{array}$} & \\
\hline \multirow{4}{*}{$\begin{array}{l}\text { Motivo Me gusta su } \\
\text { contenido }\end{array}$} & \multirow[b]{2}{*}{ No } & Recuento & & & & & & \\
\hline & & $\begin{array}{l}\text { Recuento } \\
\text { esperado }\end{array}$ & 13,2 & 37,8 & 53,8 & 13,7 & 8,5 & 127,0 \\
\hline & \multirow[b]{2}{*}{ Sí } & Recuento & 21 & 50 & 53 & 15 & 3 & 142 \\
\hline & & $\begin{array}{l}\text { Recuento } \\
\text { esperado }\end{array}$ & 14,8 & 42,2 & 60,2 & 15,3 & 9,5 & 142,0 \\
\hline \multirow{4}{*}{$\begin{array}{l}\text { Motivo Para apren- } \\
\text { der cosas nuevas }\end{array}$} & \multirow[b]{2}{*}{ No } & Recuento & 6 & 18 & 51 & 8 & 11 & 94 \\
\hline & & $\begin{array}{l}\text { Recuento } \\
\text { esperado }\end{array}$ & 9,8 & 28,0 & 39,8 & 10,1 & 6,3 & 94,0 \\
\hline & \multirow[b]{2}{*}{ Sí } & Recuento & 22 & 62 & 63 & 21 & 7 & 175 \\
\hline & & $\begin{array}{l}\text { Recuento } \\
\text { esperado }\end{array}$ & 18,2 & 52,0 & 74,2 & 18,9 & 11,7 & 175,0 \\
\hline \multirow{2}{*}{\multicolumn{2}{|c|}{ Total }} & Recuento & 28 & 80 & 114 & 29 & 18 & 269 \\
\hline & & $\begin{array}{l}\text { Recuento } \\
\text { esperado }\end{array}$ & 28,0 & 80,0 & 114,0 & 29,0 & 18,0 & 269,0 \\
\hline
\end{tabular}

Fuente: SPSS a partir de datos propios

En segundo término, se llevó a cabo una segmentación en tres grandes grupos de edad: hasta 18 años, entre 19 y 35 años y más de 35 años, agrupando los individuos de manera que fuese posible tener una muestra mínima en cada grupo para realizar los análisis bivariados. No se pudo observar una tendencia general ni diferencias importantes entre los segmentos de edad en la pregunta de si seguirían más a influencers si los hubiera, ni en la cuestión sobre si han descubierto algo que no sabían gracias a un influencer. Por el contrario, sí se observó una relación débil en la pregunta sobre si han consumido alguna cosa por recomendación de un influencer $(\mathrm{V}=0,174 \mathrm{y} \mathrm{p}=0,022)$, siendo los mayores de 35 años los que menos lo hacen y los jóvenes los que practican en mayor medida, incluso por encima de lo que cabría esperar, ya que si hubiera la misma proporción entre sí consumidores $(59,4 \%$ ) y no consumidores (40,6\%) por recomendación en todos los grupos de edad, cabría suponer menos jóvenes seguidores de recomendación de los que realmente se encuentran en la muestra.

Otro de los análisis realizados se vinculó a la variable relación con el mundo del caballo, para investigar si pudieran existir diferencias significativas entre los encuestados según su forma de relacionarse con el sector. Para ello se les dividió en cuatro categorías: practica de equitación regularmente, relación profesional, hobby, sin relación directa actual (pero sí en el pasado). Se excluyeron aquellos individuos sin relación con el mundo ecuestre para garantizar una mayor fiabilidad en el estudio. Los resultados aportaron diferencias importantes y relaciones significativas en el caso de seguir los perfiles de Federación $(\mathrm{V}=0,423$ y $\mathrm{p} \leq 0,000)$, tiendas de material hípico $(\mathrm{V}=0,495$ y $\mathrm{p} \leq 0,000)$, deportistas $(\mathrm{V}=0,435 \mathrm{y} \mathrm{p} \leq 0,000)$ y clubes o 
hípicas ( $\mathrm{V}=0,437$ y $\mathrm{p} \leq 0,000$ ), siendo aquellos que tienen una relación profesional y que practican equitación regularmente quienes siguen más a todos estos tipos de perfiles en comparación con el resto (tabla 6). En cualquier caso, no fue posible establecer relaciones significativas en el caso de los perfiles de los influencers ( $V=0,125$ y p=0,237), deduciéndose que son un tipo de perfil al que se sigue de similar modo, sin importar especialmente el vínculo personal con el mundo del caballo. El estudio también determinó que se conforman dos bloques de opinión entre quienes siguen perfiles relacionados con el mundo ecuestre preferentemente para aprender cosas nuevas $(\mathrm{V}=0,275 \mathrm{y} \mathrm{p} \leq 0,000)$, pues es este un motivo de peso para quienes practican equitación regularmente y quienes lo tienen como hobby, mientras que el grupo de profesionales y los que no tienen relación directa que no optan por esta opción. Por lo que respecta a la opinión sobre los influencers en función de la relación personal con el sector ecuestre, se evidenciaron diferencias significativas en la opinión de que modernizan la manera de mostrar el sector $(\mathrm{V}=0,226 \mathrm{y} \mathrm{p}=0,003)$, siendo los profesionales y quienes practican equitación regularmente los que más adoptan esta postura.

Tabla 6. Tipo de relación*Tipos de perfiles

\begin{tabular}{|c|c|c|c|c|c|c|c|}
\hline \multirow{2}{*}{\multicolumn{3}{|c|}{$\begin{array}{l}\text { Tabla cruzada. Relación }{ }^{*} \\
\text { Tipos de perfiles }\end{array}$}} & \multicolumn{4}{|c|}{ Relación1 } & \multirow{3}{*}{$\begin{array}{r}\text { Total } \\
82\end{array}$} \\
\hline & & & \multirow{2}{*}{$\begin{array}{c}\begin{array}{c}\text { Practico } \\
\text { equitación } \\
\text { regularmente }\end{array} \\
32 \\
\end{array}$} & \multirow{2}{*}{$\begin{array}{c}\begin{array}{c}\text { Relación } \\
\text { profesional }\end{array} \\
6\end{array}$} & \multirow{2}{*}{$\begin{array}{c}\text { Es un hobby } \\
24\end{array}$} & \multirow{2}{*}{$\begin{array}{c}\begin{array}{c}\text { No relación } \\
\text { directa actual }\end{array} \\
20\end{array}$} & \\
\hline \multirow{4}{*}{$\begin{array}{l}\text { Perfil Federación } \\
\text { Deportiva u otros } \\
\text { canales oficiales }\end{array}$} & \multirow[b]{2}{*}{ No } & Recuento & & & & & \\
\hline & & $\begin{array}{l}\text { Recuento } \\
\text { esperado }\end{array}$ & 43,6 & 16,5 & 13,4 & 8,5 & 82 \\
\hline & \multirow[b]{2}{*}{$\mathbf{S i}$} & Recuento & 111 & 48 & 20 & 8 & 187 \\
\hline & & $\begin{array}{l}\text { Recuento } \\
\text { esperado }\end{array}$ & 99,4 & 37,5 & 30,6 & 19,5 & 187 \\
\hline \multirow{4}{*}{$\begin{array}{l}\text { Perfil tiendas de } \\
\text { material hípico }\end{array}$} & \multirow[b]{2}{*}{ No } & Recuento & 26 & 6 & 19 & 24 & 75 \\
\hline & & $\begin{array}{l}\text { Recuento } \\
\text { esperado }\end{array}$ & 39,9 & 15,1 & 12,3 & 7,8 & 75 \\
\hline & \multirow[b]{2}{*}{ Si } & Recuento & 117 & 48 & 25 & 4 & 194 \\
\hline & & $\begin{array}{l}\text { Recuento } \\
\text { esperado }\end{array}$ & 103,1 & 38,9 & 31,7 & 20,2 & 194 \\
\hline \multirow{4}{*}{ Perfil deportistas } & \multirow[b]{2}{*}{ No } & Recuento & 16 & 9 & 17 & 19 & 61 \\
\hline & & $\begin{array}{l}\text { Recuento } \\
\text { esperado }\end{array}$ & 32,4 & 12,2 & 10 & 6,3 & 61 \\
\hline & \multirow[b]{2}{*}{ Si } & Recuento & 127 & 45 & 27 & 9 & 208 \\
\hline & & $\begin{array}{l}\text { Recuento } \\
\text { esperado }\end{array}$ & 110,6 & 41,8 & 34 & 21,7 & 208 \\
\hline
\end{tabular}




\begin{tabular}{|c|c|c|c|c|c|c|c|}
\hline \multirow{4}{*}{$\begin{array}{l}\text { Perfil clubes o } \\
\text { hípicas }\end{array}$} & \multirow[b]{2}{*}{ No } & Recuento & 20 & 7 & 17 & 20 & 64 \\
\hline & & $\begin{array}{l}\text { Recuento } \\
\text { esperado }\end{array}$ & 34 & 12,8 & 10,5 & 6,7 & 64 \\
\hline & \multirow[b]{2}{*}{ Si } & Recuento & 123 & 47 & 27 & 8 & 205 \\
\hline & & $\begin{array}{l}\text { Recuento } \\
\text { esperado }\end{array}$ & 109 & 41,2 & 33,5 & 21,3 & 205 \\
\hline \multirow{2}{*}{ Total } & & Recuento & 143 & 54 & 44 & 28 & 269 \\
\hline & & $\begin{array}{l}\text { Recuento } \\
\text { esperado }\end{array}$ & 143 & 54 & 44 & 28 & 269 \\
\hline
\end{tabular}

Fuente: SPSS a partir de datos propios

Tabla 7. Tipo de relación ${ }_{i}$ Has consumido por su recomendación?

\begin{tabular}{|c|c|c|c|c|c|c|c|}
\hline \multirow{2}{*}{\multicolumn{3}{|c|}{$\begin{array}{c}\text { Tabla cruzada. Relación }{ }^{*} \\
\text { ¿Has consumido por su recomendación? }\end{array}$}} & \multicolumn{5}{|c|}{ Relación1 } \\
\hline & & & \multirow{2}{*}{$\begin{array}{c}\begin{array}{c}\text { Practico } \\
\text { equitación } \\
\text { regularmente }\end{array} \\
46\end{array}$} & \multirow{2}{*}{$\begin{array}{c}\begin{array}{c}\text { Relación } \\
\text { profesional }\end{array} \\
25\end{array}$} & \multirow{2}{*}{$\begin{array}{c}\text { Es un hobby } \\
21\end{array}$} & \multirow{2}{*}{$\begin{array}{c}\begin{array}{c}\text { No relación } \\
\text { directa actual }\end{array} \\
10\end{array}$} & \multirow{2}{*}{$\begin{array}{r}\text { Total } \\
102\end{array}$} \\
\hline \multirow{4}{*}{$\begin{array}{l}\text { ¿En alguna ocasión } \\
\text { has consumido } \\
\text { algo por su } \\
\text { recomendación? }\end{array}$} & \multirow[b]{2}{*}{ No } & Recuento & & & & & \\
\hline & & $\begin{array}{l}\text { Recuento } \\
\text { esperado }\end{array}$ & 56,5 & 21,9 & 16,7 & 6,9 & 102,0 \\
\hline & \multirow[b]{2}{*}{ Sí } & Recuento & 93 & 29 & 20 & 7 & 149 \\
\hline & & $\begin{array}{l}\text { Recuento } \\
\text { esperado }\end{array}$ & 82,5 & 32,1 & 24,3 & 10,1 & 149,0 \\
\hline \multirow{4}{*}{$\begin{array}{l}\text { Si hubiera más in- } \\
\text { fluencers ecuestres, } \\
\text { ¿los seguirías? }\end{array}$} & \multirow[b]{2}{*}{ No } & Recuento & 20 & 7 & 10 & 15 & 52 \\
\hline & & $\begin{array}{l}\text { Recuento } \\
\text { esperado }\end{array}$ & 27,6 & 10,4 & 8,5 & 5,4 & 52,0 \\
\hline & \multirow{2}{*}{ Sí } & Recuento & 123 & 47 & 34 & 13 & 217 \\
\hline & & $\begin{array}{l}\text { Recuento } \\
\text { esperado }\end{array}$ & 115,4 & 43,6 & 35,5 & 22,6 & 217,0 \\
\hline \multirow{2}{*}{\multicolumn{2}{|c|}{ Total }} & Recuento & 139 & 54 & 41 & 17 & 251 \\
\hline & & $\begin{array}{l}\text { Recuento } \\
\text { esperado }\end{array}$ & 139,0 & 54,0 & 41,0 & 17,0 & 251,0 \\
\hline
\end{tabular}

Fuente: SPSS a partir de datos propios

En lo referente a la pregunta de si han consumido por recomendación de un influencer, ya sea comprar un producto o aplicar una técnica, se puede advertir que los profesionales son los que menos se dejan influenciar y que quienes no tienen una relación directa con el sector están más dispuestos a escuchar sus opiniones $(V=0,181$ y p=0,410). Por otro lado, ante la opción de seguir a perfiles del tipo influencers si existieran más, los profesionales y quienes practican equitación regu- 
larmente se muestran más receptivos $(\mathrm{V}=0,307$ y $\mathrm{p} \leq 0,000)$, al contrario de quienes tienen lo ecuestre como un hobby o no tienen relación directa con el sector, que son menos partidarios de seguir a más perfiles de este tipo (tabla 7).

Tabla 8. Tipo de relación *Medios

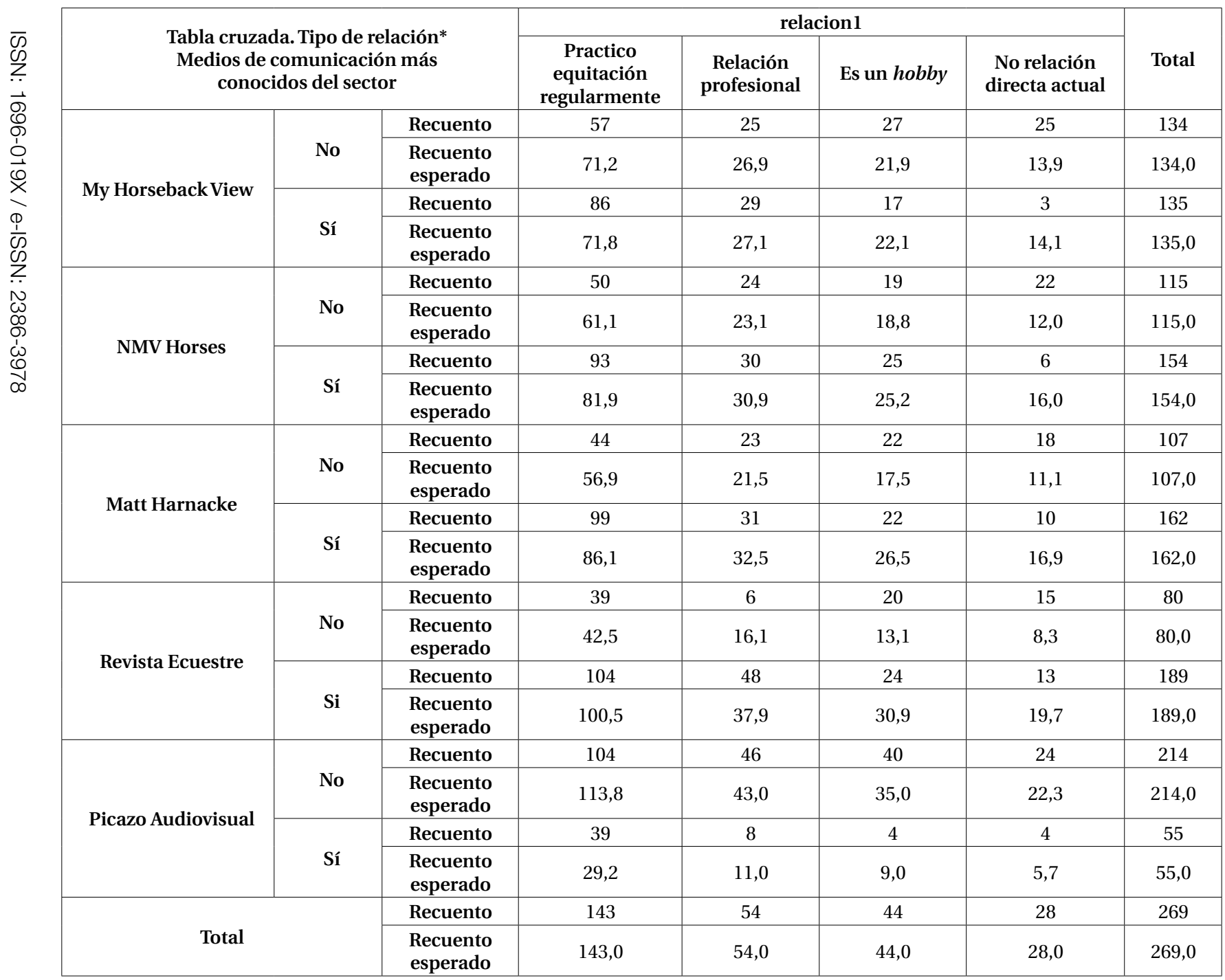


También se formalizó un análisis sobre la relación entre cada una de las categorías establecidas según su forma de relacionarse con el sector y los medios de comunicación y perfiles más conocidos del mundo ecuestre (Tabla 8). En el caso de My Horseback View ( $V=0,309$ y $\mathrm{p} \leq 0,000$ ) y de la revista Ecuestre $(\mathrm{V}=0,287$ y $\mathrm{p} \leq 0,000)$ son los profesionales y quienes practican equitación regularmente los que más conocen a este medio. Este último grupo también destaca en el conocimiento de NMV Horses ( $V=0,261$ y $p \leq 0,000)$, Matt Harnacke ( $V=0,228$ y $p=0,003)$ y Picazzo Audiovisual $(V=0,186$ y $p=0,026)$, por lo que, en definitiva, se puede sostener que son quienes siguen y conocen más medios relacionados con el sector. Por su parte, el programa televisivo TodoCaballo y la Revista Hípica Catalana son seguidos prácticamente por igual sin importar su relación con el mundo del caballo.

\subsection{Análisis cualitativo de fuentes primarias}

De modo complementario a los anteriores análisis, se planteó la realización de uno de tipo cualitativo sobre fuentes primarias, con el fin de tener una visión más completa del tema objeto de la presente investigación y de aportar una mayor riqueza a nivel metodológico, de forma que fuese posible contribuir al objetivo de conocer mejor la situación del sector, la valoración de las redes sociales y su influencia sobre la decisión de compra en este campo y la opinión que puedan tener los partícipes en el ámbito ecuestre sobre acuerdos y patrocinios con influencers. El análisis cualitativo se llevó a cabo en dos fases. En primer término, se realizó una entrevista semiestructurada en grupo a través de videoconferencia a cinco participantes de diferentes edades, todos con relación activa y directa con el mundo del caballo. Se les realizaron preguntas muy similares a las establecidas para la encuesta con el objetivo de conseguir una mayor variedad en las posibles respuestas. A continuación, se les planteó un segundo cuestionario más parecido al utilizado en la segunda fase del análisis cualitativo, una serie de entrevistas individuales a personas con diferentes funciones dentro del sector.

En esta entrevista al grupo de expertos se resolvió que existen dos tipos de influenciadores en el ámbito ecuestre, resultando los perfiles de deportistas que promocionan productos de alta gama menos efectivos que aquellos influencers que pudieran recomendar productos de menor precio, ya que el poder adquisitivo de los jinetes no siempre es tan alto como el de los profesionales. Respecto al impacto que generan los influencers en el sector todos los participantes valoraron su aportación como positiva, pues proporcionan formación y contenido de interés, acercando este deporte a más personas. Sobre la situación del sector en España se advirtió de la falta de desarrollo y modernización, no priorizando el bienestar del caballo sobre otros aspectos, subrayando la existencia de muchos clubes y entrenadores con una mentalidad anticuada que promueven una formación obsoleta que reprime el crecimiento del sector. Para ellos, el enfoque más generalizado de la equitación es su consideración como ocio, siendo el componente económico el que frustra muchas aspiraciones competitivas.

En cuanto a las entrevistas individuales realizadas, se intentó conseguir una amplia variedad de perfiles diferentes relacionados con el sector. Para ello se contactó con las dos influencers nacionales más acreditadas (Silvia, de My Horseback View y Natalia, de NMV Horses), a una influencer internacional (Carolina, de Equestrian Trend), a Otti Verdú, deportista de alto nivel, a un representante de la Real Federación de Hípica Española y a dos de clubes hípicos, uno del Real Club de Polo de Barcelona y otro del C.A.V.A. Horse Girona. A todos ellos se les planteo una entrevista similar, con muy ligeras 
variaciones, con las preguntas divididas en tres grandes bloques, a fin de obtener una visión global sobre los principales temas objeto de análisis.

Con el primer bloque de cuestiones se trataba de conocer sobre la situación de la equitación española tanto interna como en comparación con el resto de los países. La visión de la equitación española es prácticamente unitaria por parte de casi todos los entrevistados pues se estima que España está muy lejos de alcanzar a sus vecinos europeos, tanto a nivel aficionado como en la competición nacional e internacional. De esta opinión difieren la Federación y uno de los clubes, ya que estiman que el sector está muy afianzado y en crecimiento.

El propósito del segundo bloque era indagar sobre el uso y la influencia de las redes sociales en la sociedad en general y en el mundo ecuestre en particular. Todos los entrevistados apuntan que las redes sociales son un instrumento de influencia en la sociedad y en las relaciones interpersonales, provocando probablemente un mayor impacto en los más jóvenes, para quienes, en ocasiones, un mal uso de las redes sociales puede llegar a resultar peligroso en muchos sentidos. Por eso, los generadores de contenido coinciden en la gran responsabilidad que tienen al disfrutar de este poder de influencia.

Por otro lado, se sugiere que las redes también son una buena fuente de información y entretenimiento, que, bien usadas, ayudan a generar modelos de conducta adecuados con los que interactuar y aprender. Además, indudablemente, las redes pueden influir en las decisiones de compra de los consumidores, aunque, en el caso particular de este deporte, al utilizar un ser vivo, existe una mayor fidelidad a los productos ya conocidos, por lo que el poder de influencia de las redes se reduce bastante en este ámbito.

En cambio, la figura del influencer sí que es importante cuando aparece una nueva necesidad o un producto nuevo, sobre todo si tienen una menor relación directa con el animal (p.e. ropa o complementos). La gestión de las cuentas de redes sociales es realizada en su gran mayoría por ellos mismos, con excepción de la Federación y el Real Club de Polo de Barcelona. Los influencers aseguran que intentan mostrar la actualidad de este mundo, tratan de conocer más a sus seguidores, ofreciéndoles contenidos de calidad y formación y realizan promoción de los productos de sus patrocinadores.

El tercer bloque de cuestiones trataba de conocer la opinión sobre los influencers y los acuerdos que generan con las marcas. La mayor parte de los entrevistados tienen una opinión favorable de ellos, pues los influencers, al testar los productos y notificar sus propiedades, permiten a las marcas dirigirse a un nicho de mercado muy específico de forma muy directa. Para todos ellos, la relación entre influencer y marca debe encajar en cuanto a posicionamiento y valores, pues el mensaje emitido ha de reflejar la imagen de ambos. La efectividad de esta colaboración se ha refrendado en muchas ocasiones en un aumento de conocimiento y un incremento de ventas de las marcas patrocinadas. Siendo una opinión muy minoritaria la que apunta que pueden acercan el mundo del caballo a un público más general haciendo se incremente el interés de otras personas por él, lo cierto es que el papel de los influencers en el sector no es muy diferente al de otros, pues son generadores de contenidos muy específicos dirigidos a un target concreto, no siendo habitual que se conviertan en un elemento promocionador hacia el exterior, sino que más bien proporcionan un mayor conocimiento a quienes ya forman parte del mismo.

En cuanto al contenido, los influencers entrevistados destacan que su función es la de brindar un punto de vista real y más parecido al que pueden vivir los jinetes no profesionales. Se estima que en la hípica existen una gran diferencia entre los 
influencers que son jinetes profesionales, con muchos seguidores y generalmente muchos patrocinadores, cuya función en redes es mostrar sus resultados en la competición, y el resto de influencers, que suele presentar productos y generar contenido informativo, entre otros cometidos. La posibilidad de crear relaciones de patrocinio con influencers es considerada interesante de cara al futuro por algunas de las instituciones representadas en las entrevistas. En general, este tipo de relaciones son de carácter estricto y normalmente se formalizan a través de un contrato.

Analizando el conjunto de respuestas obtenidas en ambos tipos de entrevistas, resulta posible recoger aquellas que se han repetido con una mayor frecuencia por los diferentes partícipes en estos estudios cualitativos (Tabla 9). En este sentido, resulta relevante comprobar que los análisis cualitativos permiten indagar en aspectos o cuestiones concretas que podían no haber quedado suficientemente claras o evaluadas con un análisis de tipo cuantitativo, lo cual confirma la conveniencia de combinar ambos métodos en la realización de este tipo de investigaciones.

Tabla 9. Entrevistas: Puntos coincidentes más frecuentes

\begin{tabular}{|c|c|c|}
\hline & Respuesta de mayor frecuencia & Otras respuestas de frecuencia elevada \\
\hline $\begin{array}{l}\text { ¿Cómo ves la equitación en } \\
\text { España en la actualidad? }\end{array}$ & $\begin{array}{l}\text { Se carece de una cría de caballos de deporte } \\
\text { consistente y potente para tener buena } \\
\text { competición a nivel nacional. }\end{array}$ & $\begin{array}{l}\text { - La visión social de la equitación ha evolucionado, } \\
\text { siendo menos elitista. } \\
\text { - Tradicionalmente se han priorizado otros aspectos } \\
\text { antes que el desarrollo profesional del jinete. }\end{array}$ \\
\hline $\begin{array}{l}\text { "España está por detrás de } \\
\text { muchos países europeos" } \\
\text { ¿Qué opinas? }\end{array}$ & $\begin{array}{l}\text { España está muy lejos de alcanzar a sus } \\
\text { vecinos europeos tanto a nivel aficionado } \\
\text { como en la competición nacional e } \\
\text { internacional. }\end{array}$ & $\begin{array}{l}\text { - Se ha evolucionado mucho los últimos años. } \\
\text { - No siendo de los primeros países, no está tan lejos } \\
\text { (justo debajo de los cinco primeros). }\end{array}$ \\
\hline $\begin{array}{l}\text { ¿Cómo se encara la } \\
\text { equitación en España? } \\
\text { ¿Ocio o competición? }\end{array}$ & $\begin{array}{l}\text { Por lo general se estima más ocio que } \\
\text { deporte. }\end{array}$ & $\begin{array}{l}\text { - Existe una barrera económica para competir que } \\
\text { imposibilita su desarrollo. } \\
\text { - Cada vez hay más jinetes con aspiraciones } \\
\text { competitivas y/o que se dedican profesionalmente a } \\
\text { este deporte. }\end{array}$ \\
\hline $\begin{array}{l}\text { ¿Cómo afectan las redes } \\
\text { sociales a la sociedad? }\end{array}$ & $\begin{array}{l}\text { Tienen gran poder de influencia } \\
\text { condicionando sobre todo a los más jóvenes. }\end{array}$ & $\begin{array}{l}\text { - Pueden comportar consecuencias negativas, creando } \\
\text { necesidades de aprobación. } \\
\text { - Son buena fuente de información y permiten la } \\
\text { generación de comunidades. }\end{array}$ \\
\hline $\begin{array}{l}\text { ¿Crees que las redes } \\
\text { influyen en las decisiones } \\
\text { de compra? }\end{array}$ & Absolutamente sí. & $\begin{array}{l}\text { - Al tratar de productos con relación directa con el } \\
\text { caballo, las personas son más reticentes a dejarse } \\
\text { influenciar. }\end{array}$ \\
\hline $\begin{array}{l}\text { ¿Cómo gestionas tus } \\
\text { cuentas de redes sociales? }\end{array}$ & $\begin{array}{l}\text { Uso principal como fuente informativa, para } \\
\text { mostrar el día a día. }\end{array}$ & $\begin{array}{l}\text { - Proporcionando formación, opiniones y consejos a } \\
\text { los seguidores (respuesta de } \text { influencers) } \\
\text { - Informando de resultados competitivos. }\end{array}$ \\
\hline $\begin{array}{l}\text { Opinión sobre acuerdos y } \\
\text { patrocinios con influencers }\end{array}$ & $\begin{array}{l}\text { Se muestran a favor de ellos, creyendo que } \\
\text { son efectivos. }\end{array}$ & $\begin{array}{l}\text { - Los valores y el posicionamiento son muy } \\
\text { importantes al elegir el patrocinio (respuesta de } \\
\text { influencers). } \\
\text { - } \\
\text { Permiten acercar marcas a un nicho muy específico. }\end{array}$ \\
\hline
\end{tabular}




\begin{tabular}{|l|l|l|}
\hline $\begin{array}{l}\text { ¿Qué piensas de los } \\
\text { influencers en el sector } \\
\text { ecuestre? }\end{array}$ & $\begin{array}{l}\text { Generalmente a favor de ellos, } \\
\text { considerándolos una fuente de información } \\
\text { extra para el sector. }\end{array}$ & $\begin{array}{l}\text { Generan contenido, proporcionan consejos y } \\
\text { opiniones honestas (respuesta de influencers). } \\
\text { Impulsan el sector internamente, pero no lo } \\
\text { promocionan hacia el exterior. }\end{array}$ \\
\hline $\begin{array}{l}\text { ¿Has realizado patrocinios } \\
\text { con marcas? }\end{array}$ & $\begin{array}{l}\text { Sí, se suelen generar contratos muy } \\
\text { serios, especificando las características } \\
\text { de la relación (respuesta de influencers y } \\
\text { deportista). }\end{array}$ & $\begin{array}{l}\text { No se han realizado, pero en algunos casos se } \\
\text { consideran una opción interesante para el futuro } \\
\text { (respuesta del resto de entrevistados). }\end{array}$
\end{tabular}

Fuente: elaboración propia a partir de entrevistas

\section{Discusión y conclusiones}

El objetivo principal de este artículo era conocer y analizar la valoración que los diferentes grupos de interés del sector ecuestre tienen de las redes sociales y su impacto en las decisiones de compra y de los influencers especializados en equitación como elementos efectivos de comunicación. Para ello, se ha practicado triangulación metodológica, llevando a cabo tanto análisis cuantitativos como, de forma complementaria, otros de tipo cualitativo, con el fin de lograr una visión más profunda y completa del tema objeto de la investigación (Webb et al. 1966; Denzin, 1970; Bericat, 1998; Olsen, 2004; Dahlstrom, Nygaard y Crosno, 2008; Dzwigol, 2020; Forni y De-Grande, 2020). De hecho, los participantes en el estudio cualitativo han aportado valoraciones que han permitido evaluar y clarificar aspectos y posturas que difícilmente hubiera sido posible con el resto de análisis. De estas se deduce que el sector está en plena evolución positiva, pero lejos de otros países punteros, que se carece de una cría de caballos de deporte consistente y que la hípica está dejando atrás la consideración de elitista, abriéndose a más público (Arias-González, 2018).

De forma mayoritaria, aproximadamente un $70 \%$, los partícipes en actividades ecuestres practican equitación regularmente o lo hacen desde un enfoque de ocio y autorrealización personal, mientras que un $20 \%$ ejercen equitación en competición o de forma profesional. Lamentablemente, en muchos casos, la decisión de no competir no es por elección personal, sino por falta de recursos (De-la-Cruz-Ayuso, 2006). Se trata de un deporte muy feminizado en el que el $70 \%$ de las licencias federativas corresponden a mujeres (Hontangas-Carrascosa, Mestre-Sancho y Orts-Delgado, 2018; Real Federación de Hípica Española, 2018; Ministerio de Educación, Cultura y Deporte, 2019).

Los resultados del presente trabajo determinan que, en general, se considera que las redes sociales tienen una elevada influencia en las decisiones de compra, aunque se advierte también del peligro que puede suponer un mal uso de estas (Ritzer, 2001; Antón-Clavé, 2007). También se percibe que el público del sector está interesado en seguir contenidos del mundo hípico y que usan las redes sociales para ello (Ministerio de Educación, Cultura y Deporte, 2015; Santamaría-De-la-Piedra y Meana, 2017; Arias-González, 2018; IAB Spain, 2019). De hecho, un gran número de los encuestados declararon estar activos en varias redes sociales y usarlas para seguir contenido ecuestre (Ministerio de Educación, Cultura y Deporte, 2015). El 80\% admite que si hubiera más influencers los seguirían, mostrándose más favorables las mujeres, los profesionales y los que practican equitación regularmente. La mayor parte de los usuarios que siguen perfiles de contenido ecuestre en redes demandan principalmente, en torno al 80\%, aquellos de tipo informativo (federación, clubes o 
canales oficiales), mientras que un $65,1 \%$ los aprovechan como fuente de aprendizaje y formación. El 80,7\% declara haber hecho descubrimientos nuevos gracias a un influencer, mientras que un 55,4\% manifiesta haber realizado una compra o aplicado una las técnicas promocionadas por ellos, siendo los mayores de 35 años y quienes conforman el segmento profesional los grupos menos abiertos a aceptar sus recomendaciones.

Se constata, por otra parte, la existencia de dos tipos de influencers en el mundo de la equitación, el que, gracias a su actividad en redes generando contenidos de interés para el público general, se convierte en referente y adquiere la capacidad de condicionar a su audiencia (Freberg et al., 2011; Gómez-Nieto, 2018; Martínez-Sala, Monserrat-Gauchi y Segarra-Saavedra, 2019), y los deportistas de alto nivel que, al compartir resultados o promocionar productos de patrocinadores, también disfrutan de capacidad de influencia (Schlesinger, Alvarado-Herrera y Martí-Parreño, 2012). Los acuerdos entre influencers y empresas deben de ser cautelosamente elegidos, resultando aconsejable que los valores de marca y patrocinado sean coincidentes, puesto que la credibilidad de los influencers descansa en la honestidad de sus recomendaciones y opiniones (Tripp, Jensen y Carlson, 1994; Chien, Cornwell y Pappu, 2011; Braunstein-Minkove, Zhang y Trail, 2011; Rossiter y Smidts, 2012; Martínez, 2015; Gómez-Nieto, 2018).

Cabe mencionar que al ser este un deporte que implica el uso de un ser vivo, el caballo, existe una mayor reticencia a confiar en deportistas o influencers especializados en redes sociales, persistiendo una considerable fidelidad hacia productos que ya se usan o a recomendaciones de personas más próximas. En cambio, la figura del influencer sí cobra importancia ante nuevas necesidades o productos, más cuanto menor sea la relación directa con el animal (p.e. ropa o complementos). En cualquier caso, la opinión generalizada sobre los influencers es positiva, considerando que ayudan a modernizar el sector y que constituyen una buena fuente de información para acercar marcas a su nicho especifico del mercado. El análisis estadístico revela que ni la edad ni la relación que se tiene con el mundo del caballo son factores determinantes para seguir este tipo de perfiles en este sector ecuestre, lo cual apunta hacia un auge y consolidación futura de los influencers ecuestres. En definitiva, aunque el empleo de influencers para persuadir en la decisión de compra esté todavía en fase de desarrollo dentro del ámbito ecuestre, el marketing de influencers puede ser tan eficaz en este sector como lo es en otros (Castelló-Martínez y Del-Pino-Romero, 2015b). Los resultados obtenidos en esta investigación ratifican la conveniencia de utilizar los influencers en el sector ecuestre como herramienta de comunicación eficiente y útil en muchos aspectos.

\section{Referencias bibliografícas}

Alonso-Rivas, J. y Grande-Esteban, I. (2004). Comportamiento del consumidor, Decisiones y estrategia de marketing. ESIC Editorial.

Álvarez-Alday, M. y Fernández-Villarán-Ara, A. (2012). Impacto económico del ocio en el siglo XXI. Arbor, 188(754), 351-363.

Antón-Clavé, S. (2007). Investigación y conocimiento en el ámbito de las grandes instalaciones recreativas. Los parques de ocio. En M. J. Monteagudo-Sánchez (coord.) (2007). El ocio en la investigación actual: una lectura desde ámbitos, disciplinas, grupos de población y contextos geográficos (67-82). Universidad de Deusto. 
Aramendía-Muneta, M.E. (2017). Spread the Word. The Effect of Word of Mouth in e-Marketing. En G. Siegert, B. Von Rimscha \& S. Grubenmann, (eds.). Commercial Communication in the Digital Age Information or Disinformation? (227245). De Gruyter Mouton.

Arias-González, S. (2018). Comunicación del sector ecuestre en España. Análisis de caso: repercusión de los blogs hípicos frente a medios afines. Universidad Rey Juan Carlos.

Asociación Nacional de Criadores de Caballos de Pura Raza Española (2019). SICAB 2019 cierra sus puertas tras una exitosa $29^{a}$ edición de amplio respaldo institucional y de público. https://bit.ly/2QN7kAn

Bericat, E. (1998). La integración de los métodos cuantitativo y cualitativo en la investigación social: Significado y medida. Ariel.

Braunstein-Minkove, J.R.; Zhang, J.J. \& Trail, G.T. (2011). Athlete endorser effectiveness: Model development and analysis. Sport, Business, and Management: An International Journal, 1(1), 93-114.

Buttle F. \& Groeger L. (2017). Who says what to whom in what channel? A rules theoretic perspective on word-of-mouth marketing, Journal of Marketing Management, 33(13-14), 1035-1059.

Cabeza, M. C. y Prat, A. G. (2012). Ocio experiencial: antecedentes y características. Revista Arbor, 188(754), 265-281.

Campbell, C. \& Farrell, J.R. (2020). More than meets the eye: The functional components underlying influencer marketing. Business Horizons, 63(4), 469-479.

Castelló-Martínez, A. y Del-Pino-Romero, C. (2015a). La comunicación publicitaria con influencers. Redmarka. Revista Digital de Marketing Aplicado, 1(14), 21-50.

Castelló-Martínez, A. y Del-Pino-Romero, C. (2015b). Prescriptores, marcas y tuits: el marketing de influencia. aDResearch ESIC: Revista Internacional de Investigación en Comunicación, 12, 86-106.

Celaya, J. (2011). La empresa en la Web 2.0. Gestión 2000.

Chien, P. M.; Cornwell, T.B. \& Pappu, R. (2011). Sponsorship portfolio as a brand- image creation strategy. Journal of Business Research, 64, 142-149.

Clavijo-Ferreira, L., Pérez-Curiel, C., Luque-Ortiz, S. y Pedroni M. (2017). Social Media y Comunicación Corporativa: Nuevo reto en las empresas de Moda. En FJ. Herrero-Gutiérrez y C. Mateos-Martín. Del verbo al bit (2029-2059). Sociedad Latina de Comunicación Social.

Coll, P. y Micó-Sanz, J.L. (2019). Influencer Marketing in the Growth Hacking strategy of digital brands, Observatorio $\left(O B S^{*}\right), 13(2), 87-105$

Dahlstrom, R., Nygaard, A. \& Crosno, J.L. (2008). Strategic, metric, and methodological trends in marketing research and their implications for future theory and practice. Journal of Marketing Theory and Practice, 16(2), 139-152.

De-la-Cruz-Ayuso, C. (2006). Una lectura ética sobre la incidencia del ocio en nuestra sociedad. En M. Cuenca-Cabeza (2006). Aproximación multidisciplinar de los estudios de ocio (59-82). Publicaciones de la Universidad de Deusto

Deloitte (2013). Estudio del Impacto del Sector Ecuestre en España. Daemon Quest, Deloitte 
Denzin, N.K. (1970). Sociological methods: a source book. Aldine Publishing Company.

Díaz-Iglesias, L.J. (2017). Soy marca: Quiero trabajar con influencers. Profit Editorial.

Dzwigol, H. (2020). Innovation in marketing research: quantitative and qualitative analysis. Marketing and Management of Innovations, 1, 128-135.

Establés, M.J., Guerrero-Pico, M. y Contreras-Espinosa, R. S. (2019). Jugadores, escritores e influencers en redes sociales: procesos de profesionalización entre adolescentes. Revista Latina de Comunicación Social, 74, 214-236.

Federación Española de Asociaciones de Ganado Selecto (2017). Pura Raza Española, Marca España: un proyecto hecho realidad. Revista Feagas, 23(40), 34-35

Forni, P. y De-Grande, P (2020). Triangulación y métodos mixtos en las ciencias sociales contemporáneas. Revista Mexicana de Sociología, 82(1), 159-189.

Freberg, K., Graham, K., McGaughey, K. \& Freberg, L. A. (2011). Who are the social media influencers? A study of public perceptions of personality. Public Relations Review, 37(1), 90-92.

Gangadharbatla, H. (2009). Facebook Me: collective self-esteem, need to belong, and internet self-efficacy as predictors of the iGeneration's attitudes toward social networking sites. Journal of Interactive Advertising, 8(2), 5-15.

Gómez-Nieto, B. (2018). El influencer: herramienta clave en el contexto digital de la publicidad engañosa. Methaodos. Revista de ciencias sociales, 6(1), 149-156.

González-López, T. (2018). La equitación y los usos sociales del caballo a través de los textos del siglo XVIII en España. Erasmo. Revista de Historia Bajomedieval y Moderna, 5, 17-40.

Gretzel, U. (2018). Influencer marketing in travel and tourism. En M. Sigala \& U. Gretzel, (Eds.). Advances in social media for travel, tourism and hospitality: new perspectives, practice and cases (147-156). Routledge.

Grigorovici, D.M. \& Constantin, C.D. (2004). Experiencing interactive advertising beyond rich media: Impacts of ad type and presence on brand effectiveness in 3D gaming immersive virtual environments. Journal of Interactive Advertising, 5(1), 22-36.

Gutiérrez-Aragón, Ó. (2016). Fundamentos de Administración de Empresas (2a edición). Ediciones Pirámide

Herrera-Harold, H. (2012). Las redes sociales: una nueva herramienta de difusión. Revista Reflexiones, 91(2), 121-128.

Hontangas-Carrascosa, J., Mestre-Sancho, J.A. y Orts-Delgado, F. (2018). Género y deporte (El camino hacia la igualdad). Editorial Reus.

IAB Spain (2019). Estudio Anual de Redes Sociales. IAB Spain.

Instituto Nacional de Estadística (2019). Anuario Estadístico de España 2019. Instituto Nacional de Estadística.

Jin, S.V., Muqaddam, A. \& Ryu, E. (2019). Instafamous and social media influencer marketing. Marketing Intelligence \& Planning, 37(5), 567-579. 
Jhala, J. y Sharma, R. (2016). Internet Use Among Adolescents. Journal of Indian Association for Child and Adolescent Mental Health, 12(1), 36-59.

Joinson, A. (2002). Understanding the psychology of internet behaviour: virtual worlds, real lives. Palgrave Macmillan

Kadekova, Z. \& Holieninova, M. (2018). Influencer marketing as a modern phenomenon creating a new frontier of virtual opportunities. Communication Today, 9(2), 90-105.

Kimmel, A. y Kitchen, P. (2014). Word of mouth and social media. Journal of Marketing Communications, 20(1), 2-4

Logroño-Tormo, M. T. y Llopis-Goig, R. (2020). Una tipología de espectadores teatrales en función de la influencia de diversos prescriptores y el uso de canales de información. Doxa Comunicación, 30, 127-143. https://doi.org/10.31921/ doxacom.n30a6

Luque-Gil, A. M. (2006). Las rutas ecuestres como actividad deportiva, recreativa y turística. Baética. Estudios de Arte, Geografía e Historia, 28(1), 413-433.

Madrid Horse Week (2019). Dossier de prensa. IFEMA.

Martínez, J. A. (2015). David Falk: Algunas cuestiones abiertas para el marketing deportivo. RICYDE. Revista Internacional de Ciencias del Deporte, 11(40), 186-191.

Martínez-Sala, A. M., Monserrat-Gauchi, J. y Segarra-Saavedra, J. (2019). El influencer 2.0 turístico: de turista anónimo a líder de opinión. Revista Latina de Comunicación Social, 74, 1344-1365.

Mejía-Llano, J. C. (2019). Cálculo del retorno de la inversión (ROI) de redes sociales en sitios de venta (e-commerce). https:// bit.ly/3azrRQP

Mihók, Z. S. y Castejón-Montijano, R. (2016). El sector ecuestre y la economía. Archivos de Zootecnia, 65(252), 481-488.

Ministerio de Agricultura, Pesca y Alimentación (2019). El sector equino en cifras. Principales indicadores económicos. MAPA, Subdirección General de Productos Ganaderos, Dirección General de Producciones y Mercados Agrarios.

Ministerio de Educación, Cultura y Deporte (2015). Encuesta Hábitos Deportivos, 2015. MECD, Subdirección General de Estadística y Estudios, Secretaría General Técnica.

Ministerio de Educación, Cultura y Deporte (2019). Anuario de Estadísticas Deportivas 2019. MCD, División de Estadística y Estudios, Secretaría General Técnica.

Moral-Moral, M. y Fernández-Alles M. T. (2012). Nuevas tendencias del marketing: El marketing experiencial. Revista Entelequia, 14, 237-251.

Muiños-Morales, P. (2017). Los influencers en el protocolo. Revista Estudios Institucionales, 4(6), 67-78.

Navío Navarro, M.; González-Díez, L. y Puebla-Martínez, B. (2018). La formación para la gestión de las redes sociales en los grados de comunicación en España y su adecuación a las competencias demandadas por las organizaciones. Doxa Comunicación, 26, 127-143. 
Olsen, W. (2004). Triangulation in social research: qualitative and quantitative methods can really be mixed. En M. Holborn. Development in Sociology (103-121). Causeway Press.

Parreño, J.M. (2010). Marketing y videojuegos. ESIC Editorial.

Real Federación de Hípica Española (2018). Retos del sector equino en España. Jornada sobre Retos del Sector Equino en España, Ministerio de Agricultura, Pesca, Alimentación y Medio Ambiente, 25-04-2018.

Real Federación de Hípica Española (2019a). Estadísticas de competición. Evolución 2014-2019. https://bit.ly/2zeqY27

Real Federación de Hípica Española (2019b). Estimación de espectadores en competiciones hípicas nacionales e internacionales en España. https://bit.ly/2xNZNuE

Real Federación de Hípica Española (2019c). Resumen del total de licencias deportivas hípicas 2019.https://bit.ly/2RULKdG Reverter-Masia, J. y Plaza-Montero, D. (2011). Ocio, deporte y turismo: Situación actual y líneas de negocio. Revista Deporte y Sociedad, 6(16), 1-31.

Ritzer, G. (2001). Explorations in the sociology of consumption. Sage.

Rossiter, J. R. \& Smidts, A. (2012). Print advertising: Celebrity presenters. Journal of Business Research, 65, 874-879.

Sánchez-Guerrero, M.J. (2016). Desarrollo de nuevas metodologías de evaluación genética de la conformación funcional y del potencial deportivo del caballo de Pura Raza Española [Tesis Doctoral, Universidad de Córdoba].

Sánchez-Jiménez, M.A. (2018). The measurement of Return on Investment (ROI) in Social Media. Revista Espacios, 39(33), $2-14$.

Santamaría-de-la-Piedra, E. y Meana, R.J. (2017). Redes sociales y fenómeno influencer. Reflexiones desde una perspectiva psicológica. Miscelánea Comillas: Revista de Ciencias Sociales y Humanas, 75(147), 443-469.

Sanz-Marcos, P., Jiménez-Marín, G., y Elías-Zambrano, R. (2019). La incorporación de la figura del influencer en las campañas publicitarias: Consecuencias para las agencias de publicidad españolas. adComunica, Revista Científica de Estrategias, Tendencias e Innovación en Comunicación, 18, 63-86

Schlesinger, W., Alvarado-Herrera, A. y Martí-Parreño, J. (2012). Patrocinio deportivo: la implicación del espectador y sus efectos en la identificación y lealtad. Cuadernos de Gestión, 12(2), 59-76.

Segado-Boj, F, Díaz-Campo, J. y Navarro-Sierra, N. (2020). Emociones y difusión de noticias sobre el cambio climático en redes sociales. Influencia de hábitos, actitudes previas y usos y gratificaciones en universitarios. Revista Latina de Comunicación Social, 75, 245-269.

Stanton, W., Etzel, M. y Walker, B. (2007). Fundamentos de marketing. Mcgraw-Hill Interamerica.

Stubb, C., Nyström, A.G. \& Colliander, J. (2019). Influencer marketing: the impact of disclosing sponsorship compensation justification on sponsored content effectiveness. Journal of Communication Management, 23(2), 109-122.

Tirado, J. (2018). Retos del sector equino. Jornada sobre Retos del Sector Equino en España, Ministerio de Agricultura, Pesca, Alimentación y Medio Ambiente, 25-04-2018. 
Tripp, C.; Jensen, T. D. \& Carlson, L. (1994). The effects of multiple product endorsements by celebrities on consumers' attitudes and intentions. Journal of Consumer Research, 20(4), 535-547.

Venegas, A. (2015). Marcas vs Influencers: matrimonio de conveniencia. Anuncios: Semanario de Publicidad y Marketing, $1516,20-24$

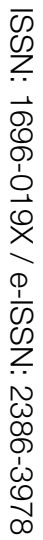

Webb, E.J., Campbell, D.T., Schwartz, R.D. \& Sechrest, L. (1966). Unobtrusive measures: Nonreactive research in the social sciences. Rand McNally. 